\title{
Templates as affixation of segment-sized units: the case of Southern Sierra Miwok*
}

\author{
Eva Zimmermann \\ University of Leipzig
}

\section{Introduction}

In this paper, I argue that certain templatic effects in Southern Sierra Miwok (SSM) follow from affixation of moras and underspecified segments. Such an analysis avoids the assumptions of syllabified X-Slots in the representation of morphemes that previous analyses for SSM argue for (Sloan 1991). In contrast, my optimalitytheoretic analysis predicts the templatic restrictions over whole strings of segments through the affixation of segment-sized phonological elements.

In SSM (Broadbent 1964, Sloan 1991), suffixes can require the preceding stem to conform to a certain shape. Such instances of 'template-requiring affixes' are also attested in Yawelmani (Archangeli 1984, 1991). A first illustrating example is given in (1) where four different forms all based on the same verb stem 'to hunt' are given. ${ }^{1}$ The stem is followed by different suffixes and it surfaces in a different shape in every context: It has a medial geminate in (1a), it has no geminate in (1b),

*For helpful discussions and comments I would like to thank the audiences of BLS 38 (Berkeley, February 2012), OCP 9 (Berlin, January 2012), the CUNY Conference on the segment (New York, January 2012), and the Kolloquium 'Neuere Arbeiten zur Grammatiktheorie' (Leipzig, January 2012) especially Jochen Trommer, Ricardo Bermúdez-Otero, Marc van Oostendorp, and Eric Raimy.

${ }^{1}$ Broadbent (1964) uses some non-standard sound symbols. She uses $N$ for the velar nasal, $T$ for alveolar voiceless stops, and $y$ for central high vowels. I replace those with the standard IPA symbols $\eta, t$, and $\dot{t}$ throughout. The symbol $Y$ represents an $u$ if the following syllable contains an $u$ or an $o$ and an $i$ elsewhere. It is the epenthetic default vowel of SSM but exists underlyingly as 


\section{Eva Zimmermann}

it has a light open second syllable in (1c), and a long vowel in the second syllable in (1d). In the following, I use the term 'template' purely descriptively to refer to such fixed sequences of long/short vowels and consonants.

(1) Templates in SSM

(Sloan 1991, 152-254)

a. hal:ik-iH-h:Y-?

'he used to hunt'

b. halik-meh-nY-haHk-te-?

'I was hunting on my way'

c. halki-paH

'a good hunter'

d. harlik-te:-nY

'to hunt along the trail'

Most verbal affixes in SSM are of this template-requiring type but there are also affixes that do not require the stem to conform to a certain templatic form. It is therefore very well possible to determine an underlying form for every stem. This distinguishes the template-effects in Miwok from templatic morphology in e.g. Semitic morphology (cf. e.g. Bat-El (2011)). In her investigation of syllable structure and templates in SSM, Sloan (1991) argues that three LH templates are particularly interesting since they require an analysis assuming (partly) syllabified X-Slots in the representation of morphemes. In contrast, I argue that the three LH templates are easily analysable in an analysis based on standard moraic theory. Such an analysis based exclusively on the independently motivated prosodic constituents of moras and segmental root nodes avoids the powerful enrichment of syllabified segmental positions as possible representations for morphemes. The paper is structured as follows: I begin with some necessary background assumptions about the phonology of SSM in section 2.1 and introduces the three LH templates in section 2.2. In section 3, I present my optimality-theoretic analysis for the three LH templates in SSM that is crucially based on the two theoretical mechanisms of moraic overwriting (section 3.1) and realization of underspecified segmental root nodes (section 3.2). I conclude in section 4.

\section{The data: LH templates in Southern Sierra Miwok}

Sierra Miwok is one of five moderately diverse Miwok languages (Penutian). It has the significant regional dialects of Northern, Southern, and Central Sierra Miwok. Southern Sierra Miwok was spoken over much of Maripose Country, in the foothills of the Sierra Nevada and has only a few semispeakers or passive speakers today

well. The symbol $H$ marks either a preceding long segment, i.e. stands for : if it is not followed by another consonant and a juncture or followed/preceded by a C-cluster (except $\mathrm{VH}+\mathrm{CH}$ ). The symbol $X$ represents length as well but in slightly different contexts. It is realized as : if a single consonant follows and none precedes the $X$. Otherwise it is not realized. 
(Hinton 1994, Golla 2011). My data for Southern Sierra Miwok are mainly from Broadbent's 1964 grammar of SSM that is also the base for the theoretical work in Sloan (1991). ${ }^{2}$ Up to now, I am aware of only one other theoretical analysis for templates in Southern Miwok and that is on the Central variety Bye and Svenonius (2011). Their analysis is quite similar to my own theoretical proposal based on the affixation of moras and root nodes, although the Central Sierra Miwok data they analyse is different from the three $\mathrm{LH}$ templates I focus on. ${ }^{3}$

\subsection{Syllable structure and stress in SSM}

SSM has a length contrast for vowels and for consonants and does not allow complex codas, onsets or clusters of identical vowels. Consequently, only the syllable types in (2) are possible in the language. Final consonants are taken to be extrametrical since CVC\# syllables count as short and CV:C\# syllables are only possible in final position.

\section{(2) Syllables in SSM}
a. Short: $\mathrm{CV}, \mathrm{CVC \#}$
b. Long: CVC, CVC: $\mathrm{CV}: \mathrm{CV}: \mathrm{C} \#$

Syllable weight is crucial for determining stress in the language. Sierra Miwok is an often cited example for iambic lengthening (Callaghan 1987, Hayes 1995, Buckley 1998): Main stress is always on the first heavy syllable and must be on the first or second syllable. The relevant constraints predicting iambic lengthening are the standard constraints given in (3) whose effect is exemplified in tableau (4) for the abstract input CVCVCV. STRESS-TO-WEIGHT is the crucial constraint ensuring that only heavy syllables are stressable, excluding for example a iambic foot with two light syllables as in candidate (4c). Consequently, some phonological strategy ensures that one of the syllables is heavy. The choice between vowel lengthening in candidate $(4 \mathrm{e}+\mathrm{f})$ and consonant epenthesis $(4 \mathrm{~d})$ is decided in favor of the former due to high-ranked HAVEPLACE penalizing insertion of an epenthetic consonant.

a. All-Foot-Left (=AFL)

(McCarthy and Prince 1993) Assign a violation mark for every left edge of a foot that is not aligned with the left edge of a prosodic word.

b. Stress-to-Weight (=StW)

(Kager 1999) Assign a violation mark for every stressed syllable that is not heavy $(=2 \mu)$.

\footnotetext{
${ }^{2}$ Another source I rely on is Freeland (1951) (written in 1936) that focusses on Central Southern Miwok but contains informations on Northern and Southern Sierra Miwok as well.

${ }^{3}$ They analyse four different stem forms in the Central variety of Sierra Miwok. The fourth stem in Central Sierra Miwok is always CVC.CV, the third stem CVC:VC, and the second stem is either CVCC or CV.CVC. The first stem varies in shape but is restricted through various demands, e.g. the necessity to be bisyllabic and to contain at least one heavy syllable.
} 
c. RHYMETYPe:IAmB (=RHT:I)

(Kager 1999) Assign a violation mark for every foot with non-final prominence.

d. PARSE- $\sigma(=$ PRS $-\sigma)$

(McCarthy and Prince 1993) Assign a violation mark for every syllable that is not parsed into a foot.

e. HavePlace (=HvPl)

(Ito and Mester 1993, Padgett 1994) Assign a violation mark for every segment without a place feature specification.

(4)

Iambic Lengthening in SSM

\begin{tabular}{|c|c|c|c|c|c|}
\hline CVCVCV & $\overline{\mathrm{AFL}}$ & RHT:I & STW & HVPL & PARSE- $\sigma$ \\
\hline a. $\quad$ CV.CV.(CV́C) & $* ! *$ & & I & & $* *$ \\
\hline b. (CV:.CV).CVC & & $* !$ & $\begin{array}{l}1 \\
\vdots\end{array}$ & & $*$ \\
\hline c. (CV.CV́).CVC & & 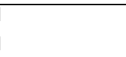 & ! $*$ ! & & $*$ \\
\hline d. (CV.CVP).CVC & & & 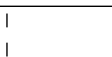 & $* !$ & $*$ \\
\hline e. (CV́:).CV.CVC & & & 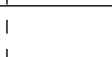 & & $* * !$ \\
\hline f. (CV.CV: $). C V C$ & & I & I & & $*$ \\
\hline
\end{tabular}

Another crucial restriction in SSM is the fact that verb stems are maximally bisyllabic. There are at least two major proposals for implementing such maximality restrictions inside OT. ${ }^{4}$ I follow Ussishkin (2005) in assuming a version of Hierarchical Alignment (Ito et al. 1996) and the constraint given in (5) demanding that stems are maximally bisyllabic.

(5) Syllable-PrWdalignment $\forall \sigma \exists \operatorname{PrWd}[\operatorname{PrWd} \supset \sigma$ and Align $(\sigma, \operatorname{PrWd})]$

(Ussishkin 2005, 188) (=Assign a violation mark for every syllable that is not aligned with the edge of some prosodic word containing it.)

I assume in the following that stems are evaluated prior to morphological concatenation (Bermúdez-Otero 2007, Kiparsky 2000, Bermúdez-Otero in preparation). This earlier optimization cycle ensures that only fully prosodified stems conforming to the bisyllabic maximality restriction enter the following optimization cycles where affixes are attached to stems.

Finally, it is important that affixes in SSM are never stressed. There are various theoretical implementations for such a generalization (cf. for example Selkirk (2004) or Trommer (2005)) and I simply follow Trommer (2011) in assuming that an undominated ALIGNMENT constraint explicitly demands that foot boundaries must coincide with boundaries of lexical morphemes.

\subsection{Three $\mathbf{L H}$ templates as a challenge for a theoretical analysis}

In the following, I concentrate on three classes of suffixes requiring that the preceding stem conforms to an LH template but vary in the shape of the final syllable.

\footnotetext{
${ }^{4}$ For discussion cf. for example ch. 2.3 in Ussishkin (2000).
} 
Templates as affixation of segment-sized units: the case of Southern Sierra Miwok

Affixes of class I require a closed final syllable as is illustrate in (6I) with the agentive suffix $-p e H$. Class II affixes require a long final vowel as e.g. the suffix - $t$ (6II). Stems preceding suffixes of class III are either CVC or CV:-final as can be seen in (6III).

(6) Examples for LH-requiring affixes

(Sloan 1991, 172-177)
I. affix-peH 'agentive'
II. affix $-t$ 'do what is characteristic of ...'
a. halik-peH 'hunter'
e. Wili:-t 'to flash, of lightening'
b. ?okoj-peH 'a nurse'
f. paTi:-t 'to take, accept'
c. liwa?-peH 'speechmaker'
g. pului-t 'to dip up'
d. koto?-peH 'guide'
h. molii-t 'shade'
III. affix -na 'benefactive'
i. kojow-na 'to tell for someone'
j. juwal-na 'to stir for someone'
k. heka:-na 'to clean for someone'
1. TeTì-na 'to gather for someone'

The variation in the stem forms preceding class III suffixes is bound to the number of underlying stem consonants. Three-consonantal stems as in $(6 \mathbf{i}+\mathbf{j})$ surface as CV.CVC whereas stems with only two consonants in their underlying representation $(6 \mathrm{k}+1)$ surface as CV.CV:. Interestingly enough, the three LH templates therefore result in only two different surface structures (CV.CVC and CV.CVV) that are distributed differently for two- and three-consonantal stems. The list in 7 makes it apparent that different phonological strategies apply to ensure that the stem conforms to these form requirements. Instances of 1. CV-metathesis, 2. realization of an additional $\dot{i}, 3$. realization of an additional 2,4 . V-shortening, 5. C-deletion, 6. V-lengthening and 7. degemination can be found.

LH templates: examples

\begin{tabular}{|ll|l|l|l|}
\hline & followed by: & class I affix & class II affix & class III affix \\
\hline a. liw:a & liwa? & liwa: & liwa: \\
b. pel:e & pele? & pele: & pele: \\
c. ko:l & kolu? & kolu: & kolu: \\
\hline e. wyli:p & wylip & wyli: & wylip \\
f. halki & halik & hali: & halik \\
g. $\quad$ wyks & wykys & wyky: & wykys \\
\hline
\end{tabular}

Sloan (1991) argues that the need to distinguish final CVC and CV:-syllables (class I and II) is strong evidence for an analysis where the three LH templates are represented as (partially) syllabified X-slots (Levin 1985). Sloan (1991) assumes a representation for the LH-templates where a light syllable with two X-Slots associated as onset and nucleus is followed by a heavy syllable with three X-Slots. The 


\section{Eva Zimmermann}

difference between class I and class II affixes is the association of the final X-Slot: it is associated to the rhyme node (=a coda consonant) or to the nucleus (=a long vowel). The alternating class III templates have a final X-slot that is not associated at all. This floating X-slot is associated with either the nucleus or the rhyme node: depending on whether a third root consonant is available on the melodic tier or whether all consonants are already associated.

I argue in the following that standard moraic theory is very well able to represent the three LH templates of SSM as well without the assumption of already syllabified morpheme representations. It is shown below how the ranking of standard faithfulness constraints penalizing the application of such phonological operations and the constraints ensuring moraic overwriting and the realization of defective phonological segments predicts the different phonological strategies that apply to ensure that the stems conform to the form requirements of the $\mathrm{LH}$ affixes.

\section{Analysis}

I argue that the three LH templates in SSM are the simple result of affixing segmentsized phonological structure, namely moras and underspecified segmental root nodes that are independently argued for in numerous analyses for non-conconcatenative morphology (e.g. Grimes (2002a), Davis and Ueda (2006), Seiler (2008), Trommer and Zimmermann (2010), Bermúdez-Otero (to appear)).

\subsection{Moraic Prefixation}

The most obvious generalization about the three LH templates is the fact that all consist of a light syllable followed by a heavy syllable. Given the stress system of the language, it is clear that the first part of the generalization is sufficient to describe the prosodic make-up of the templates: That the second syllable is heavy follows from general phonological demands of SSM if the first syllable is light. In this subsection, I show how this crucial part of all the LH templates is easily predicted from a standard device in phonology, namely affixation of a mora. I assume that in the context of every LH-requiring suffixes, a moraic prefix that is assumed to be part of the representation of the affix is added to the root. LHrequiring affixes are consequently circumfixes and consist of a mora that must be realised at the left edge of the stem and a segmental part that is realized at the right edge of the stem. ${ }^{5}$ There are possible arguments for the alternative analysis that the moraic prefix is a morpheme on its own as well but for reasons of space I cant discuss those in any detail.

The mora in SSM is now assumed to result in an overwriting effect. It is integrated into the prosodic structure of the first syllable and makes all further moraic structure

${ }^{5}$ It is therefore taken for granted that every exponent is marked for whether it attaches to the left edge or the right edge of its stem and that circumfixes are split up into two exponents with different requirements for the edge to which they attach, i.e. are suffix and prefix at the same time (Spencer 1991, Sproat 1992, Anderson 1992, Marušič 2003). 
in this syllable impossible. This overwriting follows from the constraint (8) that demands that every new association of a segment to a mora must be located at the right edge of a syllable. It is a modified DEP constraint for association lines referring to a specific syllabic position.

(8) $\quad$ DepLinK- $\left.\mu]_{\sigma}(=\mathrm{DL}]\right)$

(e.g. Morén 1999 for DepLink $\mu$ )

Assign a violation mark for every inserted association line between $\mu$ and a segment that is not at the right edge of a syllable.

The effect of DEPLINK- $\mu]_{\sigma}$ is illustrated in tableau (11). It derives the output for the stem polat to which the affix mora is added. ${ }^{6}$ In the following tableaux, I notate the affixed mora as superscribed ${ }^{\mu}$ whenever it associates to a vowel. If a vowel is associated to two moras in the output and one is the affixed mora, I distinguish between the representations $\mathrm{V}_{i}^{\mu}$ and ${ }^{\mu} \mathrm{V}:$ to indicate whether the mora is the leftmost or the rightmost mora that is associated to the vowel.

Due to the standard markedness constraint *FLOAT (e.g. Kirchner (2007)), the mora cannot remain unassociated as in candidate (11a). The undominated constraint MAX $\mu_{\mathrm{AF}}$ demands preservation of every affix mora and deletion of this affixed mora as in candidate (11b) is impossible as well. The affix mora must therefore be integrated into the prosodic structure of the base. Since it must be realized at the left edge of the stem, it must dominate the first vowel that is the leftmost possible host for a mora. ${ }^{7}$ But association to this first vowel and the resulting lengthening in candidate (11c) is excluded from DEPLINK- $\mu]_{\sigma}$. The prefixed mora associates to a vowel that is already associated to an underlying mora. The association line to this the underlying mora is the rightmost association line in the syllable and the new association to the affix mora is the leftmost association in the syllable - the configuration that is penalized by DEPLINK $-\mu]_{\sigma}$.

(9) *Float (=*FL)

(Kirchner 2007)

Assign a violation mark for every $\mu$ in the output that is not prosodically integrated.

(=it is dominated by a syllable node and dominates a segment)

(10) $\mathrm{MAX} \mu_{\mathrm{AF}}$

Assign a violation mark for every affix- $\mu$ in the input without an output correspondent.

\footnotetext{
${ }^{6}$ Recall the assumption that stems are optimized prior to concatenation. From this it follows that all vowels and non-final coda consonants are moraic in the input. The affix is assumed to be underlyingly mora-less, but nothing hinges on this assumption and the very same result is predicted if a moraic affix (very well possible given the assumption of Richness of the Base) attaches.

7 This implies that all moras are ordered with respect to each other on the moraic tier, irrespective of whether they are underlyingly associated or not.
} 
(11)

Moraic Overwriting
\begin{tabular}{|rr||c|c|c|}
\hline$\mu+$ polat & $* \mathrm{FL}$ & MAX $\mu_{\mathrm{AF}}$ & DL] \\
\hline \hline a. & $\mu$ po.lat & $* !$ & & \\
\hline b. & polat & & $* !$ & \\
\hline c. & p $^{\mu}$ or.lat & & & $* !$ \\
\hline d. & po $^{\mu}$.lat & & & \\
\hline
\end{tabular}

It is clear that the moraic overwriting in such a context with a short first syllable does not result in any surface effect: the first stem syllable po was light underlyingly and it is light in the output. But if the moraic prefix attaches to a stem with an underlyingly heavy first syllable, a surface effect of shortening is expected. This is illustrated in the tableau (12) where the stem ho:ja with a long vowel in the first syllable is optimized. As before, the prefixed mora must dominate the first vowel and it is the only possible mora in the first syllable. That the affix mora is simply added to the moras of the first syllable as in candidate $(12 b)$ - note that threemoriac syllables are generally impossible in SSM - is once again excluded from DEPLINK- $\mu]_{\sigma}$. Consequently, candidate (12c) seems to win the competition and the underlyingly long vowel is predicted to be realized as a short vowel.

Moraic overwriting with long first vowel
\begin{tabular}{|c||c|c|}
\hline$\mu+$ ho:ja & $\mathrm{MAX} \mu_{\mathrm{AF}}$ & $\mathrm{DL}]$ \\
\hline \hline a. $\quad$ ho:.ja & $* !$ & \\
\hline b. $\mathrm{h}^{\mu}$ o:ja & & $* !$ \\
\hline (国) c. $\quad \mathrm{h}^{\mu}$ o.ja & & \\
\hline
\end{tabular}

But given the knowledge of the stress system of SSS, it is clear that candidate (12c) is no possible grammatical output. A short first syllable necessarily results in a heavy second syllable. The ranking that is responsible for this iambic lengthening was illustrated in tableau (4). Quite parallel to the competition there, the optimal output for the stem $\mu+$ hoja is hoja:. Vowel lengthening applies to ensure that only heavy syllables are stressed, cf. (13A). But not only vowel lengthening applies in the context of moraic overwriting. As is shown in the summarizing tableau (13), metathesis (13C), insertion of an epenthetic vowel (13D+E) and vowel shortening (13F) apply as well. This last stem wyli:p in (13F) is particularly interesting. Recall that CV:C syllables are only possible in final position in SSM. If a stem ending in a $\mathrm{CV}: \mathrm{C}$ syllable is followed by a suffix that starts with an onset, such a syllable is expected medially: *wy.li:p.peH. Such a structure is impossible in SSM and excluded from an undominated constraint, e.g. $* \mu \mu \mu$ banning three-moraic syllables.

Candidates excluded by Stress-To-Weight, All-Foot-Left, RhymeTyPe:IAMB, and PARSE- $\sigma$ or the constraints ensuring proper realization of the moraic prefix $\left.\left(\mathrm{MAX} \mu_{\mathrm{AF}} \text {, }{ }^{*} \mathrm{FLOAT} \text {, and DEPLINK- } \mu\right]_{\sigma}\right)$ are omitted in the tableau for reasons of space. At the end of section 3, a complete ranking of all constraints in SSM is given. 
Templates as affixation of segment-sized units: the case of Southern Sierra Miwok

Class III suffixes

\begin{tabular}{|c|c|c|c|c|}
\hline & PRS- $\sigma$ & HVPL & MAXC & LIN \\
\hline \multicolumn{5}{|l|}{ A. ho:ja } \\
\hline " & * & I & I & \\
\hline b. $\quad\left(\right.$ ho $^{\mu}$.já?).peH & $*$ & $* !$ & 1 & \\
\hline \multicolumn{5}{|l|}{ B. liwa } \\
\hline a. $\quad\left(\mathrm{li}^{\mu}\right.$.wá:).peH & * & & & \\
\hline b. $\quad\left(\right.$ li $^{\mu}$.wá?).peH & * & $* !$ & & \\
\hline \multicolumn{5}{|l|}{ C. halki } \\
\hline a. $\quad\left(\right.$ ha $^{\mu}$.lí:).peH & $*$ & i & $* !$ & \\
\hline b. $\quad\left(\right.$ ha $^{\mu}$.lí?).peH & $*$ & $* !$ & $*$ & \\
\hline c. (ha $\left.{ }^{\mu} . l i ́ k\right) \cdot p e H$ & $*$ & $!$ & 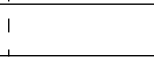 & $*$ \\
\hline \multicolumn{5}{|l|}{ D. $w \dot{k} k s$} \\
\hline a. (wi $\left.{ }^{\mu} \cdot \mathrm{k}^{\prime} \mathrm{is}\right) \cdot \mathrm{peH}$ & $*$ & $*$ & & \\
\hline b. $\quad\left(\mathrm{wi}^{\mu} \cdot \mathrm{k}^{\prime} \mathrm{i} \mathrm{i}\right) \cdot \mathrm{peH}$ & $*$ & * & $* !$ & \\
\hline \multicolumn{5}{|l|}{ E. ko:l } \\
\hline a. $\quad\left(\mathrm{ko}^{\mu} \cdot \mathrm{l}^{\prime} \mathrm{i} \mathrm{i}\right) \cdot \mathrm{peH}$ & $*$ & $*$ & & \\
\hline b. $\quad\left(\mathrm{ko}^{\mu} \cdot 1^{\prime} \mathrm{i}\right.$ ? $) \cdot \mathrm{peH}$ & * & $* * !$ & & \\
\hline \multicolumn{5}{|l|}{ F. willi:p } \\
\hline a. (wi ${ }^{\mu}$ líp).peH & $*$ & 1 & I & \\
\hline b. $\quad\left(\mathrm{wi}^{\mu}\right.$.lí:).peH & $*$ & I & $* !$ & \\
\hline
\end{tabular}

Actually, the forms that are derived by moraic overwriting are already the forms that are observed in the context of class III affixes: the presence of a moraic prefix and the ranking of DEPLINK- $\mu]_{\sigma}$ and standard markedness constraints predicts that the first syllable is light and the second syllable is heavy. Whether this second syllable has a coda consonant or a long vowel is not specified but follows from the underlying number of stem consonants. Class III affixes are therefor assumed to be a affixes with a suffixing segmental representation and a moraic prefix.

\subsection{Affixation of segmental root nodes}

The crucial difference between class III suffixes on the one hand and class I and class II suffixes on the other hand is the fact that in the latter the second syllable is determined to be either consonant- or vowel-final. In this subsection, I argue that these restrictions are predicted from the affixation of underspecified segmental root nodes rather than from the existence of prespecified syllable positions. The affixation of root nodes is another independently motivated mechanism in analyses for non-concatenative morphology, assumed to predict instances of mutation, reduplication or insertion (Bermúdez-Otero to appear, Bye and Svenonius to appear). I assume that the segmental root nodes in SSM have a minimal feature specification 


\section{Eva Zimmermann}

characterizing them for being either an obstruents/sonorant/glide or a vowel. Only the former sounds are possible final segments preceding the segmental part of a class I affix and only the latter are possible in the context of a class II affix. I assume that the feature $[ \pm$ vocalic] in the definition given in (14) is the binary feature that distinguishes these classes in SSM. Vowels are the only [+vocalic] sounds and obstruents, sonorants, and glides are all specified for [-vocalic].

(14) $[+$ vocalic $]$

(Padgett 2007, Nevins and Chitoran 2008) $=$ Absence of a narrow constriction among the articulators

The resulting representation for a class I affix is given in (15). The fully specified segmental root nodes specifying the labial voiceless stop $p$ and the vowel $e$ are preceded by a segmental root node only specified for [-voc].

(Note that I omitted a representation for the alternating length of the $e$ and the prefixing mora that is part of the affix as well.)

\section{Example: Representation for suffix class I /-peH/}

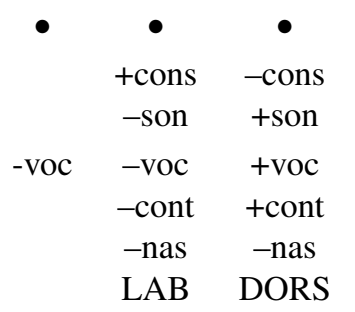

$$
\begin{gathered}
\text { abbreviated as: } \\
\text { C } \bullet \text { peH }
\end{gathered}
$$

Realization of a segmental root node that is only specified for the feature [ \pm vocalic] violates various markedness constraints demanding full specification, e.g. the markedness constraint HAVEPLACE (3e). The only option for the underspecified segmental root node to receive a place feature specification is fusion with a preceding segment. This operation violates UNIFORMITY (16) demanding that every output element corresponds only to one input element.

(16) UNIFORMiTy (=UNF) Assign a violation mark for every output element that corresponds to more than one input element.

In some contexts, however, the underspecified segmental root nodes have no chance to fuse with a preceding stem segment and receive a place feature specification without violating higher-ranked markedness demands. One such context where the segmental root node remains radically underspecified and is realized as $?$ or $\dot{i}$ respectively is exemplified in tableau (18) where a [-voc] segment precedes a vowel-final stem. The class I affix -peH is added to the root ho:ja. The mora predicts that the optimal surface representation is necessarily LH as was already 
shown in the tableau (12). But in contrast to the context there, the choice between a second heavy syllable with a coda consonant or a long vowel is not due to highranked HAVEPLACE (cf. tableau A. in (13)) but is determined by the radically underspecified [-voc] segmental root node. As for the affixed mora, a faithfulness constraint specified for affix material ensures that the segmental root node cannot simply be deleted ( $\mathrm{MAXS}_{\mathrm{AF}}$ ), cf. candidate (18a). Candidates (18b) and (18c) are possibilities to fuse the underspecified segmental root node with stem-segments. In $(18 b)$, the [-voc] root node fuses with another [-voc] segment, namely $j$. This possibility is excluded from O-CONTIGUITY (17) demanding that all elements of a morpheme must forma contiguous string if they were contiguous in the input. ${ }^{8}$ The underspecified segmental root node at the right edge of the stem can therefor only undergo fusion with the stem-final segment.

O-Contiguity $(=\mathrm{CNT})$

(Landman 2002) Assign a violation mark for every instance where phonological portions in the output that belong to the same morpheme and form a contiguous string in the input do not form a contiguous string.

('No M-internal insertion.')

Fusion with the rightmost stem segment $a$ in candidate (18c) avoids this violation but incurs a fatal violation of the faithfulness constraint IDENT[ \pm VOC]. The optimal output is therefore candidate (18d) where the underspecified segmental root node remains underspecified and is realized as default $?$.

Realization of a defective $C$

\begin{tabular}{|c|c|c|c|c|c|}
\hline$\mu+\mathrm{h}_{1} \mathrm{o}_{2} \mathrm{j}_{3} \mathrm{a}_{4}+{ }^{\mathrm{C}}{ }_{\mathrm{x}} \mathrm{p}_{\mathrm{y}} \mathrm{e}_{\mathrm{z}}^{\mathrm{r}}$ & $\mathrm{MAXS}_{\mathrm{AF}}$ & CNT & $\mathrm{ID}[ \pm \mathrm{v}]$ & HVPL & UNF \\
\hline a. $\quad\left(\mathrm{h}_{1} \mathrm{o}_{2}{ }^{\mu} \cdot \mathrm{j}_{3} \mathrm{a}_{4}\right) \cdot \mathrm{p}_{\mathrm{y}} \mathrm{e}_{\mathrm{z}} \mathrm{H}$ & $* !$ & | & | & & \\
\hline b. $\quad\left(\mathrm{h}_{1} \mathrm{o}_{2}{ }^{\mu} \cdot \mathrm{j}_{3, \mathrm{x}} \mathrm{a}_{\mathrm{i}}\right) \cdot \mathrm{p}_{\mathrm{y}} \mathrm{e}_{\mathrm{z}} \mathrm{H}$ & & $* !$ & | & & $*$ \\
\hline c. $\quad\left(\mathrm{h}_{1} \mathrm{o}_{2}{ }^{\mu} \cdot \mathrm{j}_{3} \mathrm{a}^{\prime}{ }_{4, \mathrm{x}}\right) \cdot \mathrm{p}_{\mathrm{y}} \mathrm{e}_{\mathrm{z}} \mathrm{H}$ & & I & $* !$ & & $*$ \\
\hline d. $\quad\left(\mathrm{h}_{1} \mathrm{o}_{2}{ }^{\mu} \cdot \mathrm{j}_{3} \mathrm{a}_{4} \mathrm{P}_{\mathrm{x}}\right) \cdot \mathrm{p}_{\mathrm{y}} \mathrm{e}_{\mathrm{z}} \mathrm{H}$ & & $!$ & 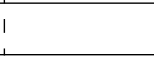 & * & \\
\hline
\end{tabular}

The derivation of class II affixes is absolutely parallel to the derivation of class I affixes we saw in (18). The underspecified segmental root node is specified for [+voc] rather than for [-voc] demanding that the stem must end in a vowel. In (19), a class II affix is attached to the same stem ho:ja. In contrast to (18), where IDENT[ \pm VOC] penalized a candidate where the defective segmental root node fused with the final stem segment, this fusion candidate in (19c) becomes optimal in (19). Since the final stem segment is [+Voc], no violation of IDENT[ \pm VOC $]$ arises.

\footnotetext{
${ }^{8}$ The definition is slightly modified compared to the original formulation in Landman (2002). The fact that O-CONTIGUITY refers only to those portions of a morphemes that form a contiguous string in the input is necessary since class I and class II affixes are assumed to be circumfixes and I took it for granted that the different portions of a morpheme are inherently specified for being realized at the left or right edge of a stem.
} 
(19)

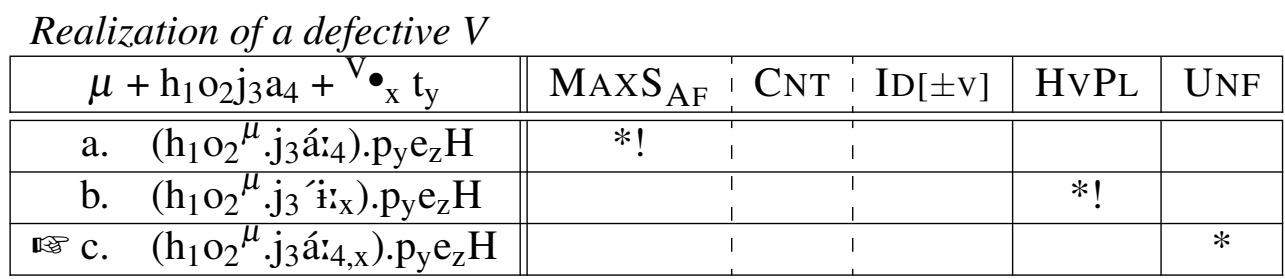

To summarize this analysis for the three different templates, the different representations for the three LH affixes are given in (20). All of them have in common that a mora attaches to the left edge of the stem ${ }^{9}$ and results in moraic overwriting as was argued in section 3.1. Class I and class II affixes have an additional radically underspecified segmental root node that attaches to the right edge of the stem and is either specified for [+voc] or [-voc].

Representations for the three LH affixes

$$
\begin{aligned}
\text { class I: } & \mu++{ }^{\mathrm{C}} \bullet \text { peH } \\
\text { class II: } & \mu++{ }^{\mathrm{V}} \bullet \mathrm{t} \\
\text { class III: } & \mu+
\end{aligned}
$$

The affixation of these independently motivated elements (moras, root nodes) together with the ranking of faithfulness and markedness constraints summarized in 21 correctly predicts the different phonological operations that apply to ensure that the stems conform to the templatic shape of a class I-III affix.

Full ranking of SSM

AFL, RHT:I, STW

$$
\begin{aligned}
& \mathrm{MAX}_{\mathrm{AF}}, \mathrm{MAXS}_{\mathrm{AF}} \\
& * \mathrm{FL}, \mathrm{DL}], \mathrm{CNT}, \mathrm{ID}[ \pm \mathrm{V}]
\end{aligned} \quad \mathrm{HVPL}, \mathrm{PRS}-\sigma, \mathrm{MAXC} \gg \quad \text { LIN, UNF }
$$

\section{Conclusion}

In this paper I argued for an analysis of three classes of template-requiring suffixes in SSM that exclusively relies on the assumption of affixed moras and underspecified segmental root nodes. The analysis is couched in standard moraic theory and therefore falsifies the claim in Sloan (1991) that the existence of three different LH templates in SSM is only analysable in a theory assuming X-Slot theory and partly syllabified representations in the input. I argued that the template-requiring affixes are underlyingly circumfixes: they contain a moraic prefixal part and a segmental suffixal part that might contain radically underspecified segmental root nodes as well. I showed that the moraic prefix results in moraic overwriting and ensures that the first syllable is necessarily light. The stress system of SSM then predicts that the second syllable must be heavy. Stems that are concatenated with a class III

${ }^{9}$ The specification for attaching to either the left or right edge is notated by the following/preceding ' + '. 
Templates as affixation of segment-sized units: the case of Southern Sierra Miwok

suffix then choose between a closed syllable or a syllable with a long vowel. Class I and class II, however, demand that the second heavy stem syllable must be either consonant- or vowel-final. This restriction about the nature of the final stem segment follows from the presence of radically underspecified segmental root nodes in the representation of morphemes.

\section{References}

Anderson, Stephen R., 1992. A-Morphous Morphology. Cambridge: Cambridge University Press.

Archangeli, Diana, 1984. Underspecification in Yawelmani Phonology and Morphology. Ph.D. thesis, MIT.

Archangeli, Diana, 1991. Syllabification and Prosodic Templates in Yawelmani. Natural Language and Linguistic Theory 9:231-284.

Bat-El, Outi, 2011. Semitic Templates. In Marc van Oostendorp, Colin J. Ewen, Elizabeth Hume, and Keren D. Rice, eds., The Blackwell Companion to Phonology, chapter 108. Blackwell.

Bermúdez-Otero, Ricardo, 2007. Morphological structure and phonological domains in Spanish denominal derivation. In Sonia Colins and Fernando Martínez-Gil, eds., Optimality-theoretic studies in Spanish phonology, 278311. Amsterdam: John Benjamins.

Bermúdez-Otero, Ricardo, in preparation. Stratal Optimality Theory. Oxford: Oxford University Press.

Bermúdez-Otero, Ricardo, to appear. The architecture of grammar and the division of labour in exponence. In Jochen Trommer, ed., The morphology and phonology of exponence: the state of the art. Oxford: Oxford University Press.

Broadbent, Sylvia, 1964. The Southern Sierra Miwok Language. University of California Press.

Buckley, Eugene, 1998. Iambic Lengthening and Final Vowels. International Journal of American Linguistics 64:179-223.

Bye, Patrick and Svenonius, Peter, 2011. Verb stem formation in Sierra Miwok redux: Syntax, morphology, and phonology. Ms., University of Troms $\varnothing$.

Bye, Patrick and Svenonius, Peter, to appear. Non-concatenative morphology as epiphenomenon. In Jochen Trommer, ed., The morphology and phonology of exponence: the state of the art. Oxford: Oxford University Press.

Callaghan, Catherine, 1987. Northern Sierra Miwok Dictionary. University of California Press.

Davis, Stuart and Ueda, Isao, 2006. Prosodic vs. morphological mora augmentation. Lexicon Forum 2:121-143.

Freeland, Lucy Shepard, 1951. Language of the Sierra Miwok. Waverly Press. Golla, Victor, 2011. California Indian languages. University of California Press.

Grimes, Stephen, 2002a. Mora Augmentation in the Alabama Imper- 
fective: an Optimality Theoretic Perspective. Online available at: http://www.ldc.upenn.edu/ sgrimes/ling.html.

Hayes, Bruce, 1995. Metrical Stress Theory: principles and case studies. Chicago: University of Chicago Press.

Hinton, Leanne, 1994. Flutes of fire, Essays on California Indian Languages. Heyday Books.

Ito, Junko, Kitagawa, Yoshihisa, and Mester, Armin, 1996. Prosodic faithfulness and correspondence: Evidence from a Japanese Argot. Journal of East Asian Linguistics 5:217-294.

Ito, Junko and Mester, Armin, 1993. Licensed segments and safe paths. Canadian Journal of Linguistics 38(2):197-213. Special issue of the Canadian Journal of Linguistics.

Kager, René, 1999. Optimality Theory. Cambridge: Cambridge University Press.

Kiparsky, Paul, 2000. Opacity and cyclicity. The Linguistic Review 17:351-67.

Kirchner, Jesse Saba, 2007. The Phonology of Lexical Underspecification. ms. University of California, online available at http://people.ucsc.edu/ kirchner/papers.html.

Landman, Meredith, 2002. Morphological Contiguity. In Angela Carpenter, Andries Coetzee, and Paul de Lacy, eds., Papers in Optimality Theory II: University of Massachusetts-Amherst Occasional Papers in Linguistics. Amherst, MA: GLSA.

Levin, Juliette, 1985. A Metrical Theory of Syllabicity. Ph.D. thesis, MIT, Cambridge, Mass.

Marušič, Lanko, 2003. *Aff-STEM-ix: On discontinuous morphology. Ms., Stony Brook University.

McCarthy, John and Prince, Alan, 1993. Prosodic Morphology. Constraint Interaction and Satisfaction. ROA 485-1201.

McCarthy, John and Prince, Alan, 1995. Faithfulness and Reduplicative Identity. In Laura Walsh Dickey Jill N. Beckman and Susanne Urbanczyk, eds., University of Massachusetts Occasional Papers in Linguistics, 249-384.

Nevins, Andrew and Chitoran, Iona, 2008. Phonological representations and the variable patterning of glides. Lingua 118:1979-1997.

Padgett, Jaye, 1994. Stricture and nasal place assimilation. Natural Language and Linguistic Theory 12:463-513.

Padgett, Jaye, 2007. Glides, vowels and features. Lingua 118:1937-1955.

Seiler, Guido, 2008. How to do things with moras: variation and change of quantity alternations across Upper German dialects. Paper presented at the International Morphology Meeting, Vienna.

Selkirk, Elisabeth, 2004. The prosodic structure of function words. In Optimality Theory in Phonology: A Reader, 464-482. Blackwell.

Sloan, Kelly Dawn, 1991. Syllables and Templates: Evidence from Southern Sierra Miwok. Ph.D. thesis, MIT.

Spencer, Andrew, 1991. Morphological Theory. Oxford: Blackwell. 
Templates as affixation of segment-sized units: the case of Southern Sierra Miwok

Sproat, Richard, 1992. Morphology and Computation. Cambridge MA: MIT Press. Trommer, Jochen, 2005. Albanian Word Stress. To appear in: Balkanistica.

Trommer, Jochen, 2011. Phonological aspects of Western Nilotic Mutation Morphology. Habil. University of Leipzig.

Trommer, Jochen and Zimmermann, Eva, 2010. Generalized Mora Affixation. talk given at the 18th Manchester Morphology Meeting, Manchester, 20th-22th May 2010.

Ussishkin, Adam, 2000. The Emergence of Fixed Prosody. Ph.D. thesis, University of California, Santa Cruz, Santa Cruz, CA. Reproduced and distributed by SLUG Pubs, Department of Linguistics, University of California, Santa Cruz, CA 95064.

Ussishkin, Adam, 2005. A Fixed Prosodic Theory of Nonconcatenative Templatic Morphology. Natural Language and Linguistic Theory 23(1):169-218.

Eva Zimmermann

Institut für Linguistik

Universität Leipzig

Beethovenstr. 15, 04107 Leipzig

Eva.Zimmermann@uni-leipzig.de 